\title{
二阶非线性微分方程的零解为全局渐近 稳定的充要条件
}

\author{
肖双发
}

（衡阳师范专科学校）

Красовский ${ }^{[1]}$ 研究了方程组 (1.1)的零解为全局渐近稳定的充分条件,本文采用定性方法, 研究了(1.1)式的零解为全局渐近稳定的必要条件,并削弱了文献 [1]中的充分条件, 从而得到 (1.1) 式的零解为全局渐近稳定的充要条件 (定理 3、4、5); 同时还研究了方程组 (2.1)的零解 为全局渐近稳定的充要条件 (定理 6).

\section{1. 研究方程组}

$$
\left\{\begin{array}{l}
d x=a x+f_{2}(y)=X(x, y), \\
d t=f_{1}(x)+b y=Y(x, y), \\
d y \\
d t
\end{array}=f_{1}=\right.
$$

其中 $a b \neq 0, f_{i}(0)=0, f_{i}(z)$ 为连续函数, 且对任何初值问题有连续依赖于初始数据的唯一 解. 令 $h_{i}(z)=\frac{f_{i}(z)}{z}, z \neq 0, i=1,2$.

引理 1 设 $a+b \geqslant 0$, 则 (1.1)式的零解不为渐近稳定.

引理 2 设 (1.1)式满足 $a+b<0$, 且有唯一的奇点 $(0,0)$, 若它的任一正半轨线位在 有界的平面部分, 则 (1.1)式的零解为全局渐近稳定.

为了方便起见,采用下列记号: $F(x, y)=a b-h_{1}(x) h_{2}(y), x \neq 0, y \neq 0 ; x_{1}\left(y_{1}\right)$ 表示 直线 $l_{1}: a x+c_{2} y=0$ 上的点的横(纵)坐标; $x_{11}\left(y_{11}\right)$ 表示直线 $l_{\mathrm{II}}: a x+c_{2}^{*} y=0$ 上的点的

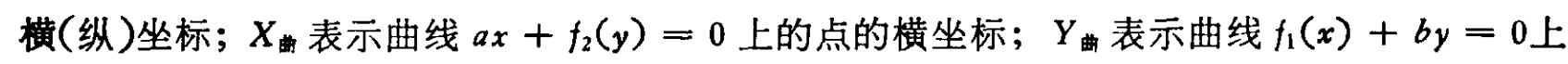
的点的纵坐标.

作等倾线 $X(x, y)=0, Y(x, y)=0$, 以确定区域内的方向场, 可证下面引理

引理 3 设 $a b>0$ 且下面的条件

$$
\left\{\begin{array}{l}
a+b<0, \\
F(x, y) \geqslant 0, \text { 且 }(1.1) \text { 式有唯一的奇点 }(0,0)
\end{array}\right.
$$

成立, 其中 $h_{1}(x), h_{2}(y)$ 为同号函数, 则 (1.1)式的零解为全局渐近稳定.

引理 4 设 $a b>0,(1.1)$ 式满足条件 (1.2), 且 $h_{1}(x), h_{2}(y)$ 中的一个为变号函数, 一 个为常号函数, 则 (1.1) 式的零解为全局渐近稳定.

定理 1 若(1.1)式满足条件(1.2), 则(1.1)式的零解为全局渐近稳定.

证 (I) 当 $a b<0$, 证明方法与文献[1] 中定理 4.5 相同 (从略).

本文1980年5月 20 日收到。 
(II) 当 $a b>0$,

(1) 设 $h_{1}(x) 、 h_{2}(y)$ 均为常号函数,由引理 3 与文献 $[1]$ 中的定理 4.3 得证;

(2) 设 $h_{1}(x) 、 h_{2}(y)$ 中有一个为变号函数,一个为常号函数,由引理 4 得证;

(3) 设 $h_{1}(x) 、 h_{2}(y)$ 均为变号函数: 显然 $h_{1}(x) 、 h_{2}(y)$ 均为有界函数, 则存在常数 $c_{1} 、 c_{2}$ 、 $c_{1}^{*} 、 c_{2}^{*}$, 有 $c_{1} c_{2}=c_{1}^{*} c_{2}^{*}=a b$, 使得

$$
c_{1} \leqslant h_{1}(x) \leqslant c_{1}^{*}, \quad c_{2} \leqslant h_{2}(y) \leqslant c_{2}^{*} .
$$

考虑曲线 $a x+f_{2}(y)=0$, 若 $y>0$, 则 $x_{I} \leqslant X_{\text {击 }} \leqslant x_{I I}$; 若 $y<0$, 则 $x_{I I} \leqslant X_{\text {畨 } \leqslant x_{1}}$.

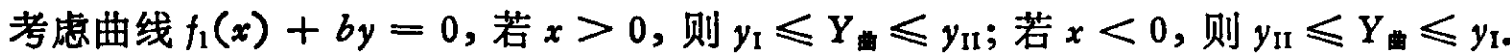

用反证法: 设某一点 $p$ 的正半轨线 $f^{+}(p, t)$ 无界，由图 1 的方向场可断定 $f^{+}(p, t)$ 必绕 原点盘旋远离而趋向无穷. 记 $q_{1}, q_{2}$ 为 $f^{+}(p, t)$ 与 $x$ 轴的正半轴的相邻的两个交点.

记 $E=\left\{x: f_{1}(x)>0\right.$ 且 $\left.x \in q_{1} q_{2}\right\}, F=\left\{x: f_{1}(x)=0\right.$ 且 $\left.x \in q_{1} q_{2}\right\}, G=\left\{x: f_{1}(x)<0\right.$ 且 $\left.x \in q_{1} q_{2}\right\}$.

设 $f_{1}\left(x_{q_{1}}\right)<0, f_{1}\left(x_{q_{2}}\right)<0$ ，

$$
(a+b) S=\int_{\overparen{a_{2} m q_{1}}+\overrightarrow{a_{1} q_{2}}} X d y-Y d x=\int_{q_{1} q_{2}}-f_{1}(x) d x \geqslant \int_{E}-f_{1}(x) d x,
$$

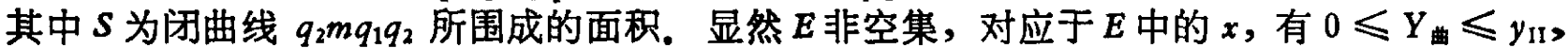
即曲线 $f_{1}(x)+b y=0, x \in E$ 恒在域 $0 T q_{2} 0$ 内, 故得

$$
(a+b) s \geqslant \int_{B}-f_{1}(x) d x=b \sigma,
$$

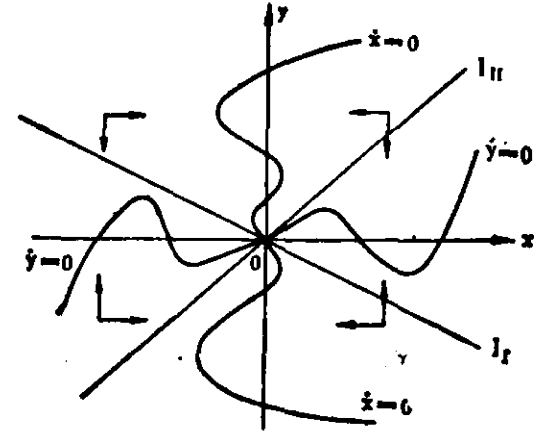

图 1

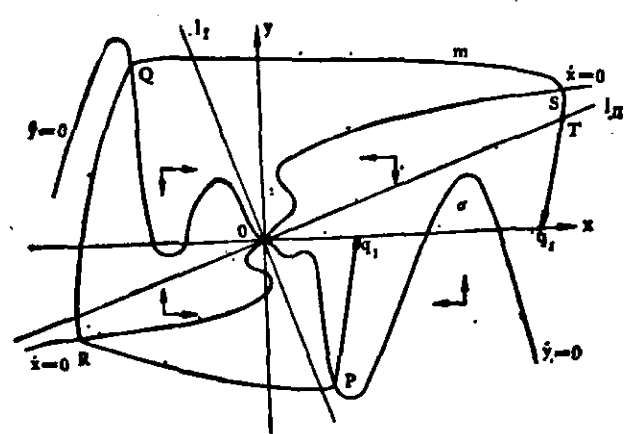

图 2

其中 $\sigma$ 为 $f_{1}(x)+b y=0, x \in E$ 与 $x$ 轴所围成的面积. $\sigma<S$, 故得 $a S+b(S-\sigma) \geqslant 0$. 所以 $a 、 b$ 中至少有一个大于零, 这与 $a<0, b<0$ 相矛盾, 故得 $f^{+}(p, t)$ 有界, 由引理 2 得 证.

同理可证 $f_{1}\left(x_{q_{1}}\right)>0, f_{1}\left(x_{q_{2}}\right)>0$ 的情形.

用证明引理 3 同样的方法可证下面定理:

定珽 2 若(1.1)式满足条件: $a+b<0, F(x, y)<0$, 则 (1.1) 式的零解不稳定.

定现 3 设 $F(x, y)$ 为常号函数,则 (1.1)式的零解为全局渐近稳定的充要条件是:

(i) $a+b<0$;

(ii) $F(x, y) \geqslant 0$ 且 $(1.1)$ 式有唯一的奇点 $(0,0)$.

证 充分性由定理 1 得证.

必要性由引理 1 得 $a+b<0$; 显然有唯一的奇点 $(0,0)$; 由定理 2 得 $F(x, y) \geqslant 0$.

很容易证明下面引理: 
引理 5 除原点外, (1.1)式在坐标轴上无奇点.

引理 6 设 (1.1) 式有非原点之奇点 $\left(x_{1}, y_{1}\right)$, 则有 $F\left(x_{1}, y_{1}\right)=0$.

引理 7 若曲线 $F(x, y)=0$ 与 $X(x, y)=0, Y(x, y)=0$ 中的任一条有非原点的交 点, 则交点必为 (1.1)式的奇点.

引理 8 (1.1)式有唯一奇点 $(0,0)$ 的充要条件是

$$
F\left(\frac{f_{2}(y)}{-a}, y\right)=0 \text { 无实数解. }
$$

引理 9 (1.1)式有唯一奇点 $(0,0)$ 的充要条件是

$$
F\left(x, \frac{f_{1}(x)}{-b}\right)=0 \text { 无实数解. }
$$

由定理 3 与引理 $8 、 9$ 可证如下定理:

定理 4 设 $F(x, y)$ 为常号函数, 则 (1.1)式的零解为全局渐近稳定的充要条件:

(i) $a+b<0$;

(ii) $F(x, y) \geqslant 0$ 且 $F\left(\frac{f_{2}(y)}{-a}, y\right)=0$ 无实数解.

定理 5 设 $F(x, y)$ 为常号函数,则 (1.1)式的零解为全局渐近稳定的充要条件是:

(i) $a+b<0$;

(ii) $F(x, y) \geqslant 0$ 且 $F\left(x, \frac{f_{1}(x)}{-b}\right)=0$ 无实数解.

\section{2. 研究方程组}

$$
\left\{\begin{array}{l}
\frac{d x}{d t}=a x+f(y), \\
\frac{d y}{d t}=c x+b y,
\end{array}\right.
$$

其中 $a b c \neq 0, f(0)=0, f(y)$ 为连续函数, 且满足初值问题有连续依赖于初始数据的唯一 解. 令 $h(y)=\frac{f(y)}{y}, y \neq 0$.

方程组 (2.1)是方程组 (1.1)的特殊情形, 故有如下的结果:

(1) 方程组 (2.1)的零解为全局渐近稳定的必要条件是: $a+b<0$;

(2) 直线 $a b-c \cdot h(y)=0, y \neq 0$, 与直线 $c x+b y=0$ 必相交, 其交点为方程组 (2.1) 的奇点.

定理 6 (2.1) 式的零解为全局渐近稳定的充要条件是:

(i) $a+b<0$;

(ii) $a b-c \cdot h(y)>0, y \neq 0$.

致谢: 本文在导师秦元勋教授的关伓与热情指导下写成, 李森林教授、何崇佑、王志成、钱祥征老师对前 面部分提出了宝贵意见,作者表示衷心感谢。

\section{参站献}

[1] Красовский Н. Н., П. М. М., 17 (1953), 6. 